\title{
The enemy within: intronic miR-26b represses its host gene, ctdsp2, to regulate neurogenesis
}

\author{
Jinju Han, Ahmet M. Denli, and Fred H. Gage ${ }^{1}$ \\ Laboratory of Genetics, Salk Institute for Biological Studies, La Jolla, California 92037, USA
}

Differentiation of multipotent stem cells occurs through the highly coordinated control of gene expression. Repressor element 1 (RE1) silencing transcription factor (REST), a master transcriptional regulator in neuronal stem cells, restricts neuronal gene expression. REST activity is context-dependent and is modified by its cofactors, such as Ctdsp2. In this issue of Genes \& Development, Dill and colleagues (pp. 25-30) report on the microRNA-mediated regulation of neural differentiation. Interestingly, this microRNA is post-transcriptionally regulated and modulates expression of its host gene, ctdsp2.

Repressor element 1 (RE1) silencing transcription factor (REST; also called neuron-specific silencing factor [NRSF]) is an essential transcription factor that represses neuronal gene expression in nonneuronal cells and neural stem cells (Lunyak and Rosenfeld 2005). During development and neural differentiation, expression of REST decreases dramatically, whereas neuron-specific gene expression increases. A large number of genes are controlled by REST, including BDNF, synapsin-I, miR-9, and miR-124 (Schoenherr and Anderson 1995; Ballas et al. 2005; Conaco et al. 2006). While the mechanisms are not yet clear, aberrations in REST function have been linked to diseases like Huntington's and Down's syndrome (Bahn et al. 2002; Zuccato et al. 2003). Somewhat paradoxically, REST has been shown to take part in tumor suppression as well as oncogenesis (Majumder 2006).

REST recognizes 21 - to 23-base-pair (bp) consensus RE1 sites that are located at regulatory regions of neural genes and directly binds to DNA through its zinc finger domains. It also recruits chromatin remodeling factors to form heterochromatin and interacts with C-terminal domain small phosphatases (CTDSPs) to inhibit RNA polymerase II (Pol II) activity for the suppression of neural gene expression (Ooi and Wood 2007).

[Keywords: miR-26b; ctdsp2; REST; neurogenesis; neuronal differentiation; zebrafish]

${ }^{1}$ Corresponding author.

E-mail gage@salk.edu.

Article is online at http://www.genesdev.org/cgi/doi/10.1101/gad.184416.111.
CTDSPs are C-class phosphatases that act on Ser 5 of the Pol II C-terminal domain (CTD) to decrease transcription (Yeo et al. 2005). The zebrafish and mammalian genomes encode at least three $c t d s p$ genes. CTDSPs are expressed in diverse organs (except the CNS) and interact with the REST complex. CTDSP enzymatic activity is required for REST function, and knockdown of CTDSP induces the neuronal differentiation of mouse embryonic carcinoma P19 cells. CTDSP2 has been shown to enhance TGF- $\beta$ signaling by the dephosphorylation of SMAD proteins and attenuates androgen receptor-mediated transcription (Thompson et al. 2006; Wrighton et al. 2006). In neuronal cells, expression of CTDSP is decreased at least in part by a neuron-specific small noncoding RNA: miR-124 (Visvanathan et al. 2007).

In this issue of Genes \& Development, Dill et al. (2012) report that an additional microRNA (miRNA), miR-26b, regulates Ctdsp2 expression during neuronal differentiation. Interestingly, miR-26b is located in an intronic region of the ctdsp2 gene, and the miRNA is transcribed together with its host gene. Dill et al. (2012) demonstrate that post-transcriptional regulation of miR-26b expression allows for the cell type-specific repression of $c t d s p 2$, providing the first experimental evidence of host gene regulation by an intronic miRNA.

ctdsp2 regulation by its intronic miRNA, miR-26b

miRNAs are small noncoding RNAs of $\sim 22$ nucleotides (nt) that control gene expression at the post-transcriptional level. miRNAs are expressed in a spatiotemporally specific manner and induce decay of target transcripts or translational suppression by binding to the 3 ' untranslated region (UTR) of target transcripts. Maturation of most miRNAs takes place through a two-step process. When a miRNA gene is transcribed, the primary transcript, called primary miRNA (pri-miRNA), forms a local hairpin structure. The nuclear ribonuclease III (RNase III) Drosha cuts the hairpin structure and releases a short hairpin-shaped RNA of $\sim 70 \mathrm{nt}$, called pre-miRNA. The pre-miRNA is exported to the cytoplasm and converted into functional, mature miRNA by the cytoplasmic RNase III Dicer (Kim et al. 2009). 
Most miRNAs are located in intragenic regions of the genome, especially in introns (Rodriguez et al. 2004). Usually, intragenic miRNAs share promoters with their host genes, so that transcription of miRNAs occurs together with the host genes (Baskerville and Bartel 2005). From one RNA transcript, two different products are generated: One is pre-miRNA cropped by Drosha during transcription, and the other one is mature host gene messenger RNA (mRNA) (Kim and Kim 2007). Since these RNAs are coexpressed both spatially and temporally, there could be a functional relationship between an intronic miRNA and its host gene (Lutter et al. 2010). Indeed, there are some experimental reports about cooperation of intronic miRNAs with their host genes for cellular function. For example, apoptosis-associated tyrosine kinase (AATK), an activator of neuronal differentiation, encodes miR-338 in its eighth intron. miR-338 mediates AATK function by suppressing antagonistic genes of neuronal differentiation, such as Nova (Barik 2008). The direct targeting of a host gene by its own intronic
miRNA was predicted in the domestic dog, Canis familiaris. The zinc finger protein 265 harbors miR-186 in an intron and a predicted miR-186-binding site in its 3' UTR (Zhou et al. 2008). However, experimental proof of such regulation has been lacking.

In this issue of Genes \& Development, Dill et al. (2012) illustrate the targeting of the ctdsp2 transcript by its intronic miRNA, miR-26b, during neuronal differentiation in early zebrafish development (Fig. 1). In their study, injection of synthetic miR-26b into one-cell stage zebrafish embryos reduced endogenous Ctdsp2 protein levels. When miR-26b was coinjected with reporter transcripts that encoded GFP and the ctdsp2 3' UTR, expression of GFP protein was suppressed, whereas the control reporter was not. This finding demonstrated that ctdsp2 mRNA was directly targeted by miR-26b. Functional depletion of miR-26b with morpholino antisense oligonucleotides (MO) in the gata2:GFP embryo resulted in the reduction of motor neurons, as evidenced by the decreased expression of GFP and the endogenous neuronal marker zinc
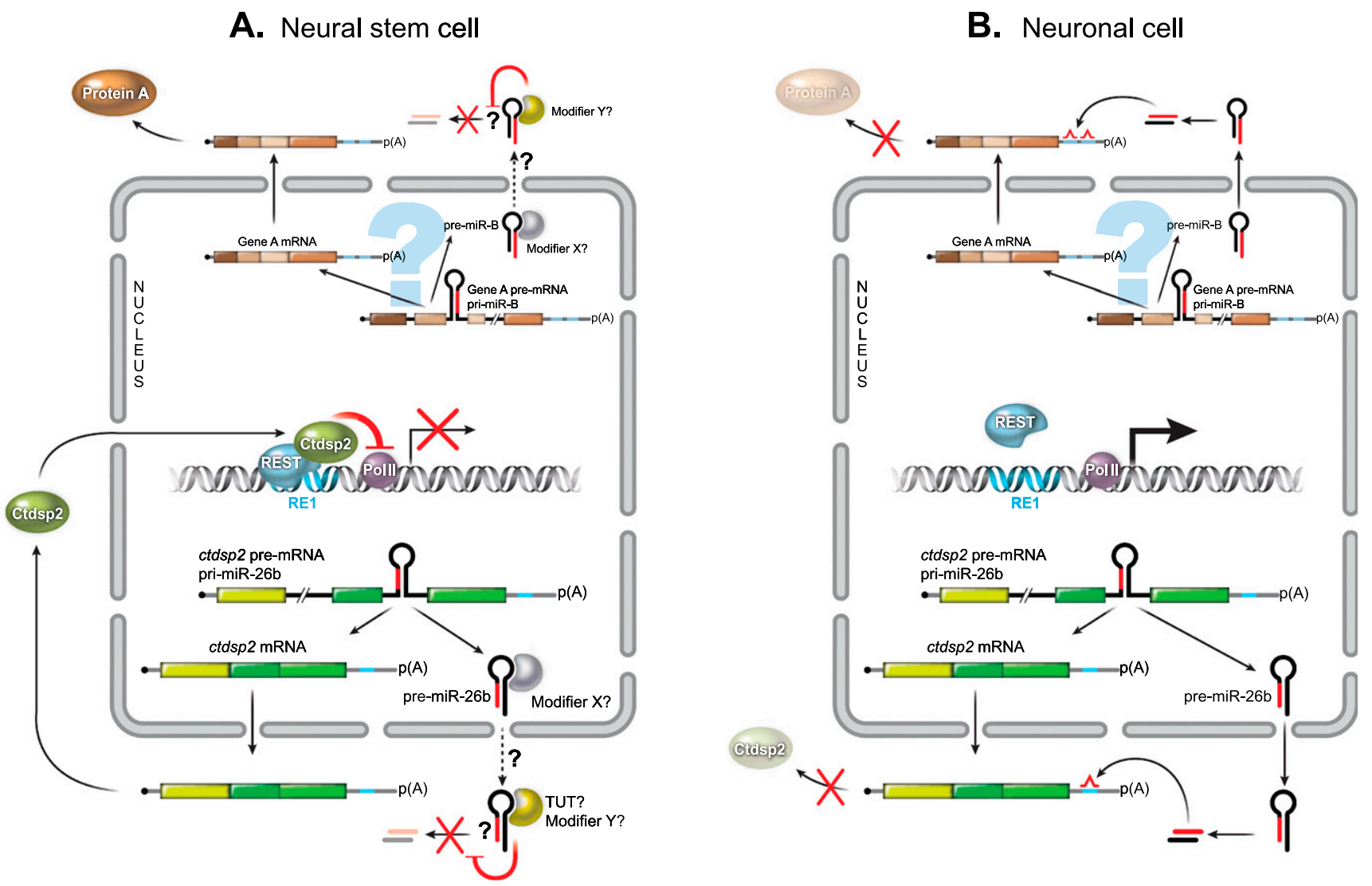

Figure 1. Decrease of host gene expression by intronic miRNA during neuronal differentiation. miR-26b (red), which targets $c t d s p 2$ mRNA (green), is located in an intronic region of ctdsp2 and is cotranscribed with its host gene (black lines denote introns). The shared RNA transcript $c t d s p 2$ pre-mRNA/pri-miR-26b generates $c t d s p 2$ mRNA and pre-miR-26b concurrently in the nucleus. $(A)$ In neural stem cells, ctdsp2 mRNA is translated into the Ctdsp2 protein, which contributes to the inhibition of neuronal gene expression by REST via suppression of Pol II activity on RE1 sites (denoted as a blue stretch of double helix). Translation of ctdsp2 is possible because pre-miR-26b is not processed into functional miR-26b. Stem cell-specific RNA-binding proteins and/or -modifying enzymes (denoted as modifier $\mathrm{X}$ in the nucleus or $\mathrm{Y}$ in the cytoplasm) may block pre-miR-26b processing. $(B)$ In differentiated neuronal cells, miR-26b is processed from pre-miR-26b and prevents $c t d s p 2$ translation. $(A, B)$ Top portions (brown) represent a general model for host gene inhibition by intronic miRNAs. 
transporter 8. Furthermore, attenuation of the neuronal differentiation markers Tuj1 and tubb5 was detected in miR-26b MO-treated fish. However, expression of the neuronal stem cell marker olig2 was not affected by miR26b knockdown. These results demonstrate that miR-26b acts during neural differentiation rather than neural stem cell maintenance. Since a single miRNA can repress hundreds of genes, it is hard to explain phenotypes that are generated by a miRNA based on just one target gene. However, it is possible to validate which gene is a major target of the miRNA and is responsible for the phenotypes. Dill et al. (2012) performed double-knockdown experiments using the gata2:GFP animals to confirm that the phenotypes were due to miR-26b MO-mediated ctdsp2 mRNA derepression. Coinjection of ctdsp2 MO rescued the decreased GFP expression caused by miR-26b MO. Dill et al. (2012) were thus able to show that suppression of ctdsp2 by miR-26b is critical for neuronal differentiation.

Since miRNAs work pleiotropically, it cannot be ruled out that there are other targets of miR-26b involved in neural differentiation. Furthermore, it is possible that miR-26b targets other REST cofactors in addition to ctdsp2. For example, one of the predicted targets for miR-26 is CoREST, an essential cofactor for REST function. The verification of additional target genes that are suppressed by miR-26 during neural differentiation will improve our understanding of miRNA-mediated regulation of neurogenesis.

\section{Post-transcriptional regulation of miRNA maturation controls host gene expression}

How can an intronic miRNA that is generated with its host transcript by a single transcription event suppress the expression of its host gene? If this suppression occurs all the time, the host gene would never be expressed. To delineate the repression mechanism, Dill et al. (2012) analyzed the expression pattern of miR-26b and its host gene, ctdsp2. As shown in their Northern blot analysis, mature miR-26b production began with the process of neurulation at $24 \mathrm{~h}$ post-fertilization (hpf), coincident with production of miR-124, the neural cell-specific miRNA and suppressor of $c t d s p$ mRNA. In contrast, premiR-26b was detected before $24 \mathrm{hpf}$-as early as in one-cell stage embryos. These data suggested that there was posttranscriptional regulation of miR-26b expression.

The spatiotemporal expression of miRNAs is determined at both the transcriptional and post-transcriptional levels. Diverse regulatory elements in the genome, including promoters, control transcription of miRNA genes. Post-transcriptional regulation of miRNA expression can occur at several steps during maturation (Siomi and Siomi 2010). General miRNA expression can be affected by changes in the activity levels of essential miRNA biogenesis components. Cell type-specific proteins can regulate the expression of particular miRNA families by the recognition of unique motifs on precursors and mature miRNAs. The let- 7 family is the best example of the post-transcriptional control of miRNA expression. In embryonic stem cells, mature let-7 is not expressed, although pri-let-7 is very abundant (Suh et al. 2004). Lin28, a stem cell-specific protein, binds to pri-let-7 and pre-let-7 through recognition of specific motifs on the loop and inhibits DROSHA and DICER processing (Heo et al. 2008; Newman et al. 2008; Viswanathan et al. 2008). In addition, the end of pre-let-7 is modified by a terminal uridylyl transferase 4 (TUT4) (Heo et al. 2009). This modification reduces DICER processing efficiency and results in the decreased generation of mature miRNAs. Conversely, KH-type splicing regulatory protein (KSRP) enhances pri-let-7 and pre-let-7 processing by binding to the terminal loop structure of the miRNA (Trabucchi et al. 2009).

Previous studies done in different experimental systems showed miR-26b to be a substrate of KSRP and TUT4. Knockdown of KSRP reduced miR-26b expression in HeLa and NIH-3T3 cell lines (Trabucchi et al. 2009). TUT4 added extra uridines to mature miR-26b in the A549 cell line (Jones et al. 2009), and the uridylated miR-26b could not suppress expression of its target gene, IL6. However, it is important to note that since the regulation of miRNAs is context-dependent, the effects of KSRP and TUT4 on miR-26b expression should be investigated in neural stem cells. In addition to KSRP and TUT4, other modifiers can affect miR-26b biogenesis at different steps, leading to the observations made in the Dill et al. (2012) study (Fig. 1). For instance, nuclear modifiers that recognize unique motifs on pre-miR-26b can regulate the export of premiR-26b. If pre-miR-26b cannot be exported into cytoplasm and is retained in the nucleus, mature miR-26b cannot be produced. Alternatively, Dicer processing can be blocked by cytoplasmic modifiers that bind to premiR-26b, or, as in the case of pre-let-7 regulation, Dicer processing efficiency can be decreased by TUT-mediated uridylation (Heo et al. 2008). The discrepancy between pre-miR-26b and mature miR-26b levels may also result from the turnover rate of mature miR-26b. Mature miRNAs have been thought to be very stable. However, recent studies have shown that extracellular signals can induce the rapid degradation of specific miRNAs (Hwang et al. 2007; Krol et al. 2010). In human and mouse liver cell lines, the adenylation of mature miR-122 by GLD2 cytoplasmic poly(A) polymerase leads to its stabilization (Katoh et al. 2009). Similarly, unknown modifiers may work on mature miR-26b to affect its stability. Finding such modifications of miR-26b will be instrumental in understanding the nature of miR-26b regulation. Further experimentation in cell culture systems may be useful to identify miR-26b targets and post-transcriptional regulators.

\section{Perspective}

Expression correlations between mature miRNA and miRNA precursors have been made in cancer cell lines (Thomson et al. 2006; Lee et al. 2008). While miRNA precursor expression status is fairly stable, mature miRNA expression patterns do change depending on cellular status. These widespread expression changes suggest that 
there may be other miRNA candidates that can be regulated at the post-transcriptional level during differentiation. The post-transcriptional regulation of miRNA maturation has been observed in stem cell populations. It is possible that the candidate miRNAs may be expressed in stem cells and decrease with differentiation (Fig. 2). These kinds of regulation can occur for intronic miRNAs as well as intergenic miRNAs.

As discussed, the intronic miRNA of $c t d s p 2$, miR-26b, contributes to the down-regulation of host gene expression in differentiated neurons. In neural stem cells, miR-26b is repressed, and Ctdsp2 collaborates with REST to inhibit neural gene expression. However, what triggers pre-miR$26 \mathrm{~b}$ processing to generate mature $\mathrm{miR}-26 \mathrm{~b}$ remains to be determined.

The miR-26 family is composed of miR-26a and miR-26b, which are generated from four different precursors: premiR-26a-1, pre-miR-26a-2, pre-miR-26a-3, and pre-miR-26b. All of the miR-26 precursors are located in intronic regions of $c t d s p$ genes, and pre-miR-26s are coexpressed during neural differentiation. Expression of $c t d s p$ genes is diminished in neuronal lineages during development, and their functions may be partially redundant (Zohn and Brivanlou 2001; Yeo et al. 2005). In fact, it is highly probable that each $c t d s p$ gene can be regulated by its own intronic miR-26. However, there may be functional differences between these family members that are too subtle to be detected by current experimental designs. In glioblastomas, human miR-26 expression correlates with CTDSP2 but not with CTDSPL (Kim et al. 2010). Analyses of mRNA expression patterns of ctdsp genes and miR-26-binding sites in different systems may provide clues about the conservation of this regulatory mechanism between intronic miRNAs and the host gene family.

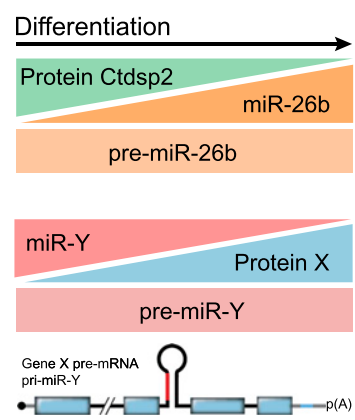

Figure 2. Potential post-transcriptional regulation of miRNAs in stem cell differentiation. (Top panel) Pre-miR-26b is expressed continuously during differentiation from stem cells (pale orange). However, as differentiation proceeds, production of miR26b from pre-miR-26b increases (orange) and reduces Ctdsp2 protein levels (green). (Middle panel) It remains to be determined whether a form of post-transcriptional regulation exists to limit production of mature intronic miRNAs (miR-Y in pink) to stem cells, leading to the protein expression of the host gene (Protein X in blue) in differentiated cells. (Bottom panel) Schematic of Gene X and intronic miR-Y that is described in the middle panel. Blue boxes and the black line represent exons and introns of Gene X, respectively. Mature miRNA is marked in red.
As shown by Dill et al. (2012), ctdsp2 is expressed in the presence of mature miR-26b in nonneuronal tissues. Therefore, one can speculate that different regulatory interactions may exist between $c t d s p 2$ and miR-26b. In nonneuronal tissues, miR-26b may be responsible for the fine-tuning of $c t d s p 2$ expression. Also, it is possible that ctdsp2 mRNA can escape from miR-26b-mediated suppression. For instance, miRNA-binding sites on a transcript can be hidden by changing tertiary structures of the 3' UTR (Ameres et al. 2007; Kertesz et al. 2007). Ultimately, while a regulatory relationship between mRNAs and miRNAs that are cotranscribed is a very interesting possibility, it remains to be seen how widespread this mode of regulation is.

\section{Acknowledgments}

This work is supported by the Helmsley Foundation. J.H. is a Salk Institute Fellow of the Life Science Research Foundation.

\section{References}

Ameres SL, Martinez J, Schroeder R. 2007. Molecular basis for target RNA recognition and cleavage by human RISC. Cell 130: 101-112.

Bahn S, Mimmack M, Ryan M, Caldwell MA, Jauniaux E, Starkey M, Svendsen CN, Emson P. 2002. Neuronal target genes of the neuron-restrictive silencer factor in neurospheres derived from fetuses with Down's syndrome: A gene expression study. Lancet 359: 310-315.

Ballas N, Grunseich C, Lu DD, Speh JC, Mandel G. 2005. REST and its corepressors mediate plasticity of neuronal gene chromatin throughout neurogenesis. Cell 121: 645-657.

Barik S. 2008. An intronic microRNA silences genes that are functionally antagonistic to its host gene. Nucleic Acids Res 36: 5232-5241.

Baskerville S, Bartel DP. 2005. Microarray profiling of microRNAs reveals frequent coexpression with neighboring miRNAs and host genes. RNA 11: 241-247.

Conaco C, Otto S, Han JJ, Mandel G. 2006. Reciprocal actions of REST and a microRNA promote neuronal identity. Proc Natl Acad Sci 103: 2422-2427.

Dill H, Linder B, Fehr A, Fischer U. 2012. Intronic miR-26b controls neuronal differentiation by repressing its host transcript, ctdsp2. Genes Dev (this issue). doi: 10.1101/gad. 177774.111 .

Heo I, Joo C, Cho J, Ha M, Han J, Kim VN. 2008. Lin28 mediates the terminal uridylation of let-7 precursor microRNA. Mol Cell 32: 276-284.

Heo I, Joo C, Kim YK, Ha M, Yoon MJ, Cho J, Yeom KH, Han J, Kim VN. 2009. TUT4 in concert with Lin28 suppresses microRNA biogenesis through pre-microRNA uridylation. Cell 138: 696-708.

Hwang HW, Wentzel EA, Mendell JT. 2007. A hexanucleotide element directs microRNA nuclear import. Science 315: 97-100.

Jones SW, Watkins G, Le Good N, Roberts S, Murphy CL, Brockbank SM, Needham MR, Read SJ, Newham P. 2009. The identification of differentially expressed microRNA in osteoarthritic tissue that modulate the production of TNF- $\alpha$ and MMP13. Osteoarthritis Cartilage 17: 464-472.

Katoh T, Sakaguchi Y, Miyauchi K, Suzuki T, Kashiwabara S, Baba T, Suzuki T. 2009. Selective stabilization of mammalian microRNAs by $3^{\prime}$ adenylation mediated by the cytoplasmic poly(A) polymerase GLD-2. Genes Dev 23: 433-438. 
Kertesz M, Iovino N, Unnerstall U, Gaul U, Segal E. 2007. The role of site accessibility in microRNA target recognition. Nat Genet 39: 1278-1284.

Kim YK, Kim VN. 2007. Processing of intronic microRNAs. EMBO J 26: 775-783.

Kim VN, Han J, Siomi MC. 2009. Biogenesis of small RNAs in animals. Nat Rev Mol Cell Biol 10: 126-139.

Kim H, Huang W, Jiang X, Pennicooke B, Park PJ, Johnson MD. 2010. Integrative genome analysis reveals an oncomir/oncogene cluster regulating glioblastoma survivorship. Proc Natl Acad Sci 107: 2183-2188.

Krol J, Busskamp V, Markiewicz I, Stadler MB, Ribi S, Richter J, Duebel J, Bicker S, Fehling HJ, Schubeler D, et al. 2010. Characterizing light-regulated retinal microRNAs reveals rapid turnover as a common property of neuronal microRNAs. Cell 141: 618-631.

Lee EJ, Baek M, Gusev Y, Brackett DJ, Nuovo GJ, Schmittgen TD. 2008. Systematic evaluation of microRNA processing patterns in tissues, cell lines, and tumors. RNA 14: 35-42.

Lunyak VV, Rosenfeld MG. 2005. No rest for REST: REST/NRSF regulation of neurogenesis. Cell 121: 499-501.

Lutter D, Marr C, Krumsiek J, Lang EW, Theis FJ. 2010. Intronic microRNAs support their host genes by mediating synergistic and antagonistic regulatory effects. BMC Genomics 11: 224. doi: 10.1186/1471-2164-11-224.

Majumder S. 2006. REST in good times and bad: Roles in tumor suppressor and oncogenic activities. Cell Cycle 5: 1929_ 1935.

Newman MA, Thomson JM, Hammond SM. 2008. Lin-28 interaction with the Let-7 precursor loop mediates regulated microRNA processing. RNA 14: 1539-1549.

Ooi L, Wood IC. 2007. Chromatin crosstalk in development and disease: Lessons from REST. Nat Rev Genet 8: 544-554.

Rodriguez A, Griffiths-Jones S, Ashurst JL, Bradley A. 2004 Identification of mammalian microRNA host genes and transcription units. Genome Res 14: 1902-1910.

Schoenherr CJ, Anderson DJ. 1995. Silencing is golden: Negative regulation in the control of neuronal gene transcription. Curr Opin Neurobiol 5: 566-571.

Siomi H, Siomi MC. 2010. Posttranscriptional regulation of microRNA biogenesis in animals. Mol Cell 38: 323-332.

Suh MR, Lee Y, Kim JY, Kim SK, Moon SH, Lee JY, Cha KY, Chung HM, Yoon HS, Moon SY, et al. 2004. Human embryonic stem cells express a unique set of microRNAs. Dev Biol 270: 488-498.

Thompson J, Lepikhova T, Teixido-Travesa N, Whitehead MA, Palvimo JJ, Janne OA. 2006. Small carboxyl-terminal domain phosphatase 2 attenuates androgen-dependent transcription. EMBO J 25: 2757-2767.

Thomson JM, Newman M, Parker JS, Morin-Kensicki EM, Wright T, Hammond SM. 2006. Extensive post-transcriptional regulation of microRNAs and its implications for cancer. Genes Dev 20: 2202-2207.

Trabucchi M, Briata P, Garcia-Mayoral M, Haase AD, Filipowicz W, Ramos A, Gherzi R, Rosenfeld MG. 2009. The RNA binding protein KSRP promotes the biogenesis of a subset of microRNAs. Nature 459: 1010-1014.

Visvanathan J, Lee S, Lee B, Lee JW, Lee SK. 2007. The microRNA miR-124 antagonizes the anti-neural REST/SCP1 pathway during embryonic CNS development. Genes Dev 21: 744 749.

Viswanathan SR, Daley GQ, Gregory RI. 2008. Selective blockade of microRNA processing by Lin28. Science 320: 97-100.

Wrighton KH, Willis D, Long J, Liu F, Lin X, Feng XH. 2006. Small C-terminal domain phosphatases dephosphorylate the regulatory linker regions of Smad2 and Smad3 to enhance transforming growth factor- $\beta$ signaling. I Biol Chem 281: 38365-38375.

Yeo M, Lee SK, Lee B, Ruiz EC, Pfaff SL, Gill GN. 2005. Small CTD phosphatases function in silencing neuronal gene expression. Science 307: 596-600.

Zhou D, Li S, Wen J, Gong X, Xu L, Luo Y. 2008. Genome-wide computational analyses of microRNAs and their targets from Canis familiaris. Comput Biol Chem 32: 60-65.

Zohn IE, Brivanlou AH. 2001. Expression cloning of Xenopus Os4, an evolutionarily conserved gene, which induces mesoderm and dorsal axis. Dev Biol 239: 118-131.

Zuccato C, Tartari M, Crotti A, Goffredo D, Valenza M, Conti L, Cataudella T, Leavitt BR, Hayden MR, Timmusk T, et al. 2003. Huntingtin interacts with REST/NRSF to modulate the transcription of NRSE-controlled neuronal genes. Nat Genet 35: 76-83. 


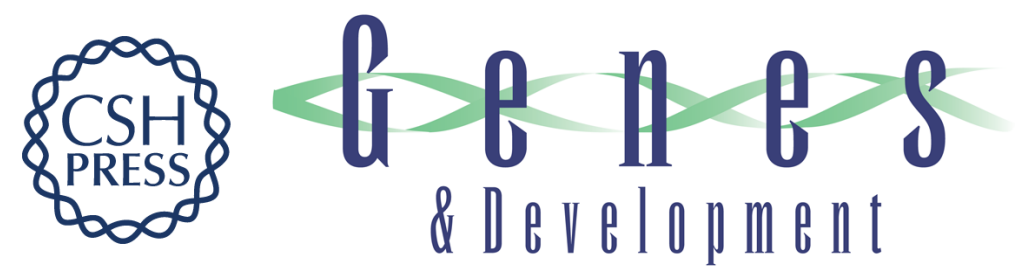

\section{The enemy within: intronic miR-26b represses its host gene, ctdsp2, to regulate neurogenesis}

Jinju Han, Ahmet M. Denli and Fred H. Gage

Genes Dev. 2012, 26:

Access the most recent version at doi:10.1101/gad.184416.111 $\begin{array}{cl}\text { Related Content } & \begin{array}{l}\text { Intronic miR-26b controls neuronal differentiation by repressing its host transcript, } \\ \text { ctdsp2 } \\ \text { Holger Dill, Bastian Linder, Alexander Fehr, et al. } \\ \text { Genes Dev. January, 2012 26: 25-30 }\end{array} \\ \text { References } & \begin{array}{l}\text { This article cites } 36 \text { articles, 14 of which can be accessed free at: } \\ \text { http://genesdev.cshlp.org/content/26/1/6.full.html\#ref-list-1 }\end{array} \\ & \begin{array}{l}\text { Articles cited in: } \\ \text { http://genesdev.cshlp.org/content/26/1/6.full.html\#related-urls }\end{array} \\ \text { License } & \begin{array}{l}\text { Receive free email alerts when new articles cite this article - sign up in the box at the top } \\ \text { right corner of the article or click here. }\end{array}\end{array}$

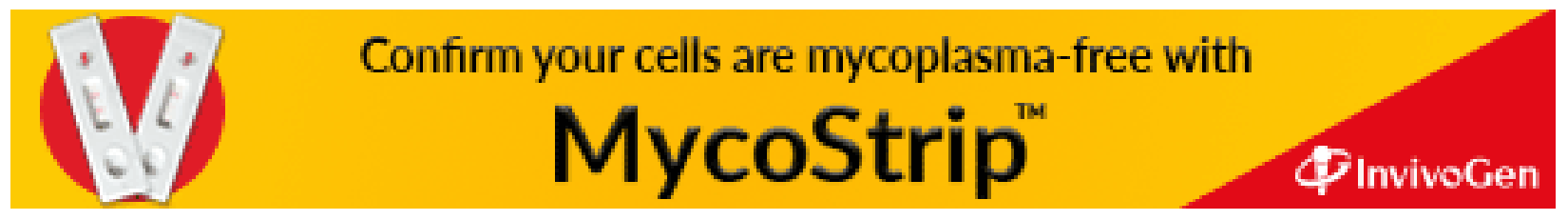

